\title{
Occupational asthma due to unheated polyvinylchloride resin dust
}

\author{
H S LEE, ${ }^{1}$ J YAP, ${ }^{2}$ Y T WANG, ${ }^{2}$ C S LEE, ${ }^{1}$ K T TAN, ${ }^{\prime}$ S C POH ${ }^{2}$ \\ From the Department of Industrial Health, ${ }^{1}$ Ministry of Labour, and Medical Unit III, ${ }^{2}$ Tan Tock Seng \\ Hospital, Singapore
}

ABSTRACT Polyvinylchloride (PVC) resins are widely used in industry. Asthma due to the thermats degradation products of PVC are well documented. In this first case of occupational asthma due to unheated PVC resin dust the patient was exposed to PVC resin dust during the mixing of chemicalș used for making plastic seals for bottle caps.

Meatwrappers' asthma and asthma due to the thermal degradation products of polyvinylchloride (PVC) are well documented..$^{1-6}$ Pneumoconiosis ${ }^{7-9}$ and interstitial pneumonitis $^{10}$ among workers exposed to PVC dust have been reported. Respiratory symptoms and abnormalities of lung function and of the chest radiograph have been described in surveys of workers exposed to PVC dust. ${ }^{11} 12$ We report the first case of asthma induced by occupational exposure to unheated PVC resin dust.

\section{Case report}

A 32 year old man worked for 14 years in a factory manufacturing bottle caps. Each metal cap was lined with a plastic seal on its inner surface. Both the fabrication of the metal caps and the injection moulding process of making plastic seals were carried out in the main production hall of the factory. The PVC resin mixture for the injection moulding process was prepared in a fairly large air conditioned room that was separated from the main production hall. For the past eight years the patient worked in this mixing room where he was exposed to PVC resin dust and other chemicals during mixing.

He started to have episodes of cough and breathlessness about five years after working in the mixing room. Initially, the frequency of symptoms was once in three to four months. During the past year, however, his symptoms had occurred almost daily and he had to depend on a ventolin inhaler for relief. He worked a five day week from 0730 to 1630 . His symptoms usually started at about 0200 or 0300 . Symptoms improved on weekends and holidays.
There was no associated rhinitis. He had no historg of asthma or atopy. His sister had a history of asthmao

\section{OCCUPATIONAL EXPOSURE}

The preparation of PVC resin mixture in the mixing room was observed and the exposure dust concentras tion monitored. Three types of chemicals were blende together to form the mixture: (i) PVC resin, a white powder, (ii) dioctylphthalate or Di-2-ethylhexylphghe alate(DOP), a plasticiser in the form of a clear gily liquid, and (iii) a paste containing azodicarbonamide (a plastics blowing or foaming agent), colouring agẹp and stabilisers. The PVC resin itself was a mixture of three grades of PVC resin: types A, B, and C. Type was an emulsion resin with no stabilisers added, type $\mathbf{B}$ an emulsion resin that had been stabilised against hea and type $C$ a suspension resin with no stabilisero added. The ratio of $A: B: C$ was $3: 1: 0 \cdot 7$. The paste containing azodicarbonamide and the liquid DOPF were first placed in a tank, then five bags $(120 \mathrm{~kg})$ of PVC resins were manually poured into the tank. The pouring process was visibly dusty and took about $1 \overline{0}$ minutes. No local exhaust ventilation was provided.

A quartz crystal microbalance cascade impacto was used to monitor the dust concentrations in the breathing zone of a worker during the pouring of PV resins. The average concentrations of exposure to the respirable $(<10 \mu \mathrm{m})$ and non-respirable dust wers $0.16 \mathrm{mg} / \mathrm{m}^{3}$ and $0.37 \mathrm{mg} / \mathrm{m}^{3}$ respectively. The aerodynamic diameter of the respirable dust ranged from 1 to $9 \mu \mathrm{m}$. The background total dust concentration was $0.02 \mathrm{mg} / \mathrm{m}^{3}$. The threshold limit value of PVE is $5 \mathrm{mg} / \mathrm{m}^{3}$ for respirable dust. ${ }^{13}$

After the pouring of the PVC resins, the liquid mixture was mechanically blended for about 45 mino utes. This later process was not dusty and was totall enclosed. The blended mixture was then transporte 
out of the mixing room to the main production area where it was used to make the plastic seals for the bottle caps.

A total of six batches of PVC resin mixture was made each day over an eight hour work shift by two workers who were confined to the mixing room and did no work in the main production area.

The other worker had no symptoms. There was, however, a further worker who had developed episodes of cough and breathlessness about three years after working in the mixing room. His symptoms occurred two to three hours after starting work and sometimes in the evening after work. He left the factory about five years ago. His symptoms have improved but occasionally he still has asthmatic attacks associated with upper respiratory tract infections. He was not keen to have any medical investigations.

\section{SERIAL MEASUREMENTS OF PEAK FLOW AT HOME} AND WORK

Peak expiratory flow rate was measured every three hours from waking to sleeping over a three week period (fig 1). The mean peak flow rate improved during the weeks at home and deteriorated during the working week. The fall in minimum peak flow rate on one day in each of the two weeks at home probably suggests some non-specific bronchial hyperreactivity.

\section{BRONCHIAL PROVOCATION TESTING}

Bronchial provocation testing was carried out on an inpatient basis. The patient had been transferred from the mixing room about six weeks before. On the first day no provocation was carried out and a baseline peak flow rate obtained. On the second day provocation was carried out by the worker using a spoon to transfer lactose powder between two compartments of

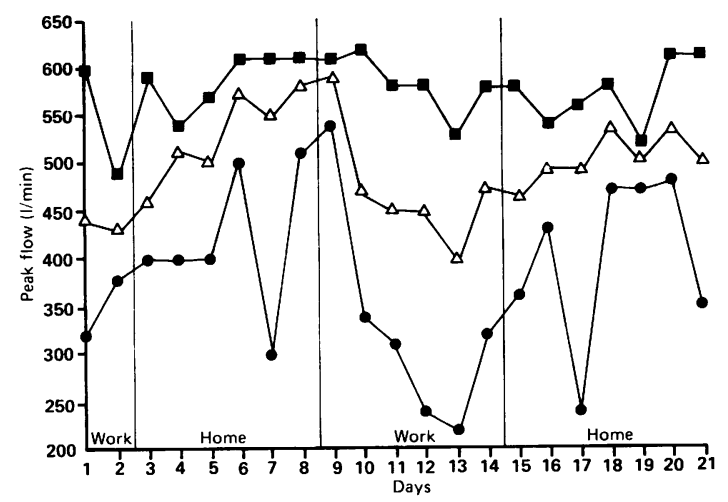

Fig $1 \square$ Daily maximum, $\triangle$ mean, and $\bigcirc$ minimum peak expiratory flow.

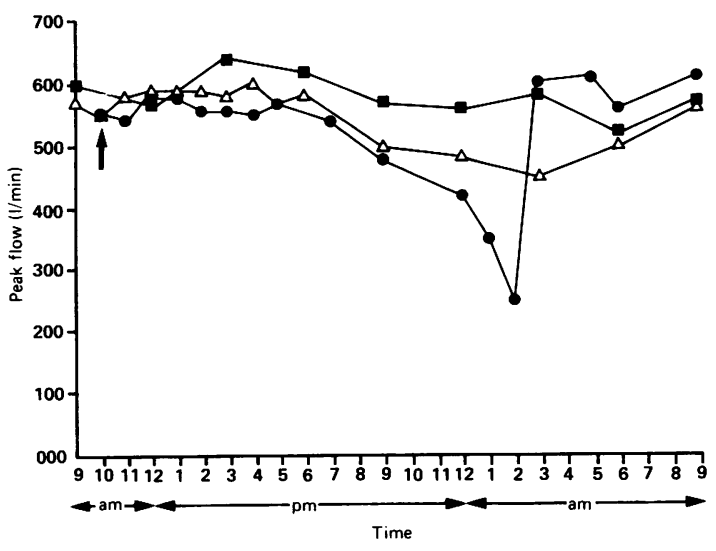

Fig 2 Peak expiratory flow baseline ( $\square$ day 1) and after exposure to lactose $(\triangle$ day 2$)$ and to $P V C$ resin dust at room temperature $(-$ day 3$)$. Arrow indicates time of exposure on days 2 and 3.

a tray for 20 minutes. The average concentrations of exposure to lactose dust were $0 \cdot 13 \mathrm{mg} / \mathrm{m}^{3}$ for respirable dust and $0.48 \mathrm{mg} / \mathrm{m}^{3}$ for non-respirable dust. The diurnal variation in the peak flow rate was $18 \%$. On the third day provocation was carried out with PVC resin dust for 20 minutes using the same procedure. The average concentrations of exposure to the PVC resin dust during the provocation were $0.12 \mathrm{mg} / \mathrm{m}^{3}$ for respirable dust and $0.20 \mathrm{mg} / \mathrm{m}^{3}$ for non-respirable dust. The peak flow rate started to fall about nine hours after exposure and reached a maximum reduction of about $58 \%$ of the baseline 16 hours after exposure. Nebulised ventolin was administered and the peak flow improved after that (fig 2). No provocdtion test was done with the liquid DOP and the paste containing azodicarbonamide.

\section{OTHER INVESTIGATIONS}

Chest $x$ ray examination did not show any evidence of pneumoconiosis. The patient had non-specific bronchial hyperreactivity as assessed by histamine inhalation challenge, the $\mathrm{PD}_{20} \mathrm{FEV}_{1}$ being $0.095 \mu \mathrm{mol}$. Skin prick testing to common environmental allergens was positive to house dust mite, feathers, and cat fur.

\section{Discussion}

Our patient had occupational asthma from exposure to PVC resin dust. Based on the history, another worker who had already left the factory probably also had occupational asthma from the PVC resins. Our patient was also exposed to DOP and azodicarbonamide. Azodicarbonamide dust is known to induce asthma. ${ }^{61415}$ So far DOP and other phthalate esters 
have not been identified as inducing asthma. ${ }^{616}$ The azodicarbonamide was in paste form and the DOP in liquid form. As the process only involved mixing the constituents at room temperature it was unlikely that any fume, dust, or vapour would be generated from these two chemicals. On the other hand, the pouring of PVC resin was visibly dusty. Thus we suspected that the PVC resin dust was the most likely causative agent. This was confirmed by the bronchial provocation test.

PVC resins are produced by four basic processes: suspension, emulsion, bulk, and solution polymerisation. PVC suspension resins are usually dust free and granular. PVC emulsion resins are small particles containing little free monomer. ${ }^{17}$ PVC resins are generally used with admixtures of stabilisers (to retard degradation), lubricants, plasticisers (to increase the flexibility of the final plastic), blowing agents, and pigments depending on the specific requirements. ${ }^{13}$ The PVC resin used in our case was a mixture of the suspension and emulsion types. The plasticiser, blowing agent, and pigment were only added during the mixing process. According to the supplier, the PVC resin was $98.5 \%$ pure. Only one of the three grades was prestabilised against heat. We do not know the type of stabiliser used but commonly used stabilisers include lead soaps and salts, barium cadmium soaps, and cadmium zinc soaps. ${ }^{17}$ These are not known to cause asthma. They are also not likely to cause asthma.

The most likely cause of the occupational asthma, we believe, is the PVC dust itself. This case differs from the asthma caused by the degradation products of PVC. The combustion of PVC causes the formation of highly irritant substances such as hydrogen chloride and phosgene. ${ }^{13}$ Emissions from hot wire cutting of PVC packaging film include hydrogen chloride and dioctyl adipate. ${ }^{4}$ Our patient was exposed only to PVC resin dust at room temperature.

PVC resins are widely used in industry. PVC resin dust has for many years been considered a nuisance. Circumstances of exposure may vary depending on the type of PVC resin and the method of use. This case has shown that PVC resin dust may cause asthma and steps should be taken to reduce occupational exposure to the dust.
We thank Dr W H Phoon, director, Department $\overline{\text { बे }}$ Industrial Health, for his comments and the mar agement and workers of the factory for their cooperas tion in the investigations.

\section{References}

1 Sokol WN, Aelony Y, Beall GN. Meat-wrapper's asthma, a new syndrome? JAMA 1973;226:639-41.

2 Andrasch RH, Bardana EJ, Koster F, Pirofsky B. Clinical and bronchial provocation studies in patients with meatwrappers asthma. J Allergy Clin Immunol 1976;58:291-8.

3 Johnson J, Anderson WH. Meat-wrappers asthma-a case study J Occup Med 1976;18:102-4.

4 Vandervont R, Brooke SM. Polyvinyl chloride film therms decomposition products as an occupational illness. Environg mental exposures and toxicology. J Occup Med 1977;19:188-9 D

5 Brooks SM, Vandervont R. Polyvinyl chloride film therma decomposition products as an occupational illness. Clinicaff studies. J Occup Med 1977;19:192-6.

6 Hagmar L, Nielsen J, Skerfving S. Clinical features and epidemiology of occupational obstructive respiratory diseasso caused by small molecular weight organic chemicals. Monod Allergy 1987;21:42-58.

7 Szende B, Lapis K, Nemes A, Pinter A. Pneumoconiosis caused b尹 the inhalation of polyvinyl chloride dust. Med Lav 1970;61. 433-6.

8 Arnaud A, Pommier de Santi P, Garbe L, Payan H, Charpin Polyvinyl chloride pneumoconiosis. Thorax 1978;33:19-25. (1)

9 Mastrangelo G, Manno M, Marcer G, et al. Polyvinyl chloride pneumoconiosis: epidemiological study of exposed workers. Ф Occup Med 1979;21:540-2.

10 Cordasco EM, Demeter SL, Kerkay J, et al. Pulmonary manifesta0 tions of vinyl and polyvinyl chloride (interstitial lung dise्sefe Newer aspects. Chest 1978;6:828-34.

11 Soutar CA, Copland LH, Thornley PE, et al. Epidemiolagेç study of respiratory disease in workers exposed to polyviny chloride dust. Thorax 1980;35:644-52.

12 Soutar CA, Gauld S. Clinical studies of workers exposed polyvinylchloride dust. Thorax 1983;38:834-9.

13 Viola PL. Vinyl and polyvinyl chloride. In: Encyclopaedia \& occupational health and safety. Vol 2. Geneva: International. Labour Office, 1983:2256-60.

14 Ferris BG, Peters JM, Burgess WA, Cherry RV. Apparent effect of an azodicarbonamide on the lung: a preliminary report. JOccu理 Med 1977;19:424-5.

15 Slovak AJM. Occupational asthma caused by a plastics blowing agent, azodicarbonamide. Thorax 1981;36:906-9.

16 Nielsen J, Akesson B, Skerfving S. Phthalate ester exposure. A levels and health of workers processing polyvinylchloride. $A$ h Ind Hyg Ass 1985;46:643-7.

17 Wheeler RN Jr. Poly (vinyl chloride) processes and products Environ Health Perspect 1981;41:123-8. 